\title{
UTILIZATION OF COMPUTER SIMULATION FOR DETECTION NON-STANDARD SITUATIONS WITHIN SINGLE-TRACK LINES
}

\author{
Jan Fikejz ${ }^{(a)}$, Jan Merta ${ }^{(b)}$ \\ (a,b) Department of Software Technologies, FEI, University of Pardubice, Pardubice, Czech Republic \\ (a) Jan.Fikejz@upce.cz ${ }^{\text {(b) }} \underline{\text { Jan.Merta@student.upce.cz, }}$
}

\begin{abstract}
This article deals with the use of computer simulation for induction and detection of non-standard/crisis situations within single-track railways. First, attention is paid to the collection and evaluation of historical data, which are then used for the designed simulator. The article then focuses on the design of a simulation tool for inducing non-standard/crisis situations within a monitored segment of a railway network. Simulation tool is then used for selected experiments.
\end{abstract}

Keywords: Railway infrastructure models, train positioning, railway traffic simulation

\section{INTRODUCTION}

One of the areas of rail transport is the positioning of rolling stock. Localization of these transport elements can be looked at differently. Depending on the importance and utilization of the line, localization systems with different reliability and accuracy can be deployed. Regional lines are not such an object of interest compared to major or international corridors, but in each country, regional lines form a significant part of the railway network. These lines have their own specifics, such as the fact that they often consist of single-track lines, have lower utilization ratio, lower speed limits, but also lower demands on security and localisation systems. In 2011, the European Commission published a White Paper (Kom 2011), which sets out objectives and actions for the transport sector with an outlook to 2050. The White Paper sets out, among other things, a roadmap for a unified European transport area - the creation of a competitive, resource-efficient transport system. From the perspective of rail transport, it is mainly the strengthening of rail transport on main and regional lines and the introduction of intelligent systems using, for example, ERTMS or GNSS. From this perspective, regional lines should be given appropriate attention, too.

\section{STATE OF ART}

There are a number of different national solutions around the world that deal with the localisation of rolling stock on regional lines, most of which use GNSS, balises, or odometers. Wireless information transmission is then done mainly via mobile networks GSM-R (Global System for Mobile - Railway) or classic GSM technology. Let us mention at least some national systems focused on regional lines.

\subsection{ERTMS Regional - Švédsko}

This system was developed in cooperation with the International Union of Railways (UIC), Swedish Transport Administration (Trafikverket) and the company Bombardier (Low cost ERTMS 2014). ERTMS Regional is a simpler and cheaper variant of the ERTMS/ETCS L1 to L2 system as a suitable option for lines with lower traffic density. The designed system is operated on a single-track line with a total length of 143 $\mathrm{km}$ with five stations and a traffic density of sixteen trains per day, with planned further extension to lines in total length of $565 \mathrm{~km}$. The basic principle lies in the periodic sending (every 6 seconds) of position information to the Train Control Centre $(T C C)$, which issues a running permit. Information about the position of RS (rolling stock) is obtained from the odometer, while the accuracy of the position is done by means of balises installed in stations and on the track with fixed spacing of five kilometres. The GSM-R and GSM mobile networks are used for the transmission of information.

\subsection{LOCOPROL - Francie}

Another system used in France is the LOCOPROL technological solution (Libbrecht and Sturesson 2005), based on the name Low Cost Satellite based train location system for signalling and train Protection for Low density traffic railway lines. The system was developed under the leadership of the company ALSTOM and other partners from Belgium, Germany and France as part of a research project focusing on the use of satellite navigation for low-density traffic railway lines. The LOCOPROL system is used on a single-track regional line of $35 \mathrm{~km}$. The basic principle again uses radio block centre $(R B C)$ to which information about the location of the RS on the line is sent and information about the running permit is also received from $R B C$. The information about the location of the RS is collected by satellite navigation (GPS, Gleans, Galileo in the future) and the odometer. Refining the position in critical places (usually in stations and station throats or in places of 
radio shadow) is realized using installed balises. The position locator is integrated directly into the on-board ETCS and the mobile network of the public operator is used to transmit information. The integrity of the train is under the control of the driver.

\subsection{InSat - Itálie}

In Italy, a system called 3InSat (Train Integrated Safety Satellite System) was developed under the auspices of Ansaldo STS in cooperation with other foreign partners. The project was completed in 2014 and the resulting system is used on a single-track regional line in Sardinia with a total length of $50 \mathrm{~km}$. Again, it uses $R C B$ to collect location data and issues running permits. Location information of the RS is obtained from satellite navigation (GPS EGNOS, Galileo) and the odometer. The mobile network GSM, TETRA (Trans-European Trunked Radio) and satellite communication to transmit the information. The architecture of the solution is based on ETCS L2 (Mouna 2013).

\subsection{SATLOC - Rumunsko}

The SATLOC system was established under the auspices of UIC in cooperation with eleven organizations from six countries around the world with the support of the European Space Agency (ESA). The project focuses and the development and innovative use of GNSS to support rail traffic management within regional lines. Furthermore, the objectives of the project are focused on the design of new operational standards, software and hardware solutions and services.

Currently, the SATLOC system is operated in test mode on a single-track line of $27 \mathrm{~km}$. The designed and tested system meets ETCS L2 standards (Redding 2014).

\subsubsection{Status in the Czech Republic}

The infrastructure of the Czech railway network currently has over nine and a half thousand kilometres of lines, which are divided into four categories (see Figure 1):

- Corridor lines registered in the European railway system with a total length of $1402 \mathrm{~km}$ — pink colour,

- National lines registered on the European railway system with a total length of $1189 \mathrm{~km}$ - green colour;

- National lines not registered on the European railway system with a total length of $3748 \mathrm{~km}$ — red colour;

- Regional lines not registered on the European railway system with a total length of $3232 \mathrm{~km}$ -blue colour.

Single-track lines account for approximately $7607 \mathrm{~km}$, which corresponds to approximately $\mathbf{8 0 \%}$ of the total length of all lines. The regional lines as such account for over 33\% of the lines (Kolář 2014, Dorazil 2008).

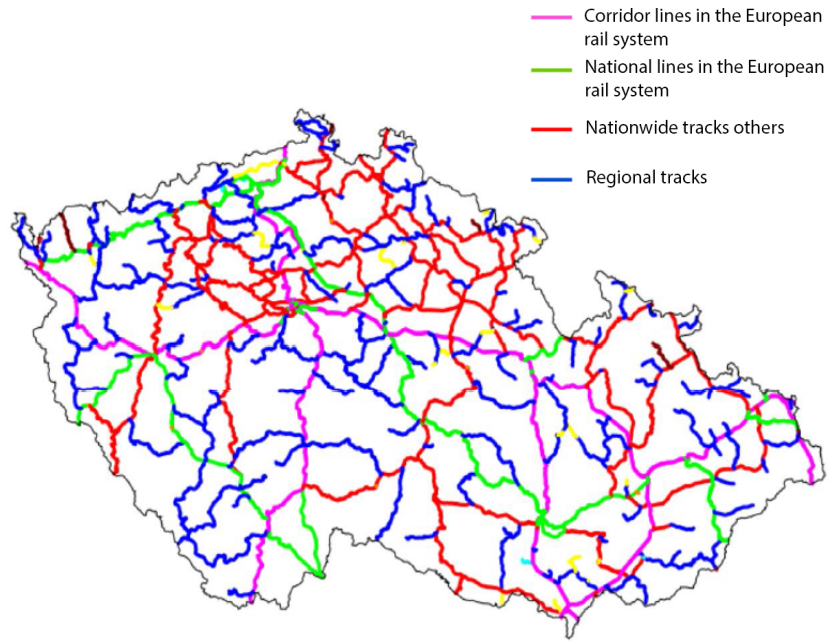

Figure 1: Structure of lines in $\check{C} R$.

Single-track and, above all, regional lines are perceived as less important for reasons of lower utilization, and this corresponds to a lower level of safety. On these lines it is often possible to register only that the train left the station or arrived at the station. Yet hundreds of emergency events have occurred over the last decade.

\section{LOCALIZATION}

Generally, localisation is prone to a wide range of approaches on how to identify the position of trains on a track. Put simply, localisation may be divided into the following three groups:

- localization without the use of GNSS,

- GNSS using localization,

- GNSS-based, involving further support systems.

Our approach of trains localisation access to tracks is based on the correct pairing up of GPS information on position, provided by communication terminals, with the nearest vertex or edge of the graph (Fikejz and Kavička, 2011; Fikejz and Řzanina 2014.). The discovered vertex/hectometre post disposes not only of a multidimensional key in the form of a GPS coordinate, it is also linked, through definition sections, to further information concerning the railway network infrastructure.

View of the situation that the model of railway infrastructure is stored in the database Oracle we can use the native database functions and operators (Kothuri et al. 2007). The SDO_NN (nearest neighbor) operator was selected in view of realising this unique trains localisation approach. The aforementioned operator searches for a geometric object that is closest to the object entered (like a point, for example). In other words, it is possible to find the nearest vertex, or more precisely edge in a model, from the current position trains, Figure 2 . 


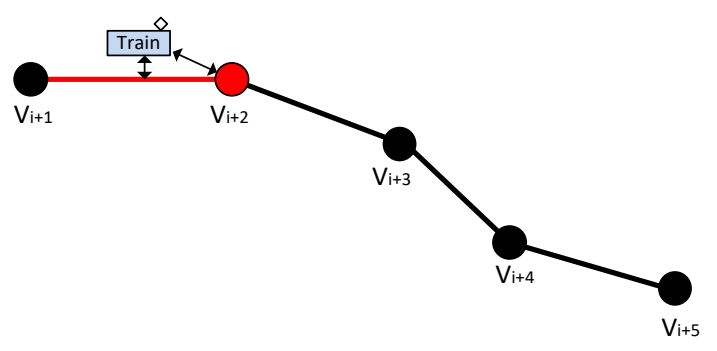

Figure 2: Main concept of localization

The actual detection of the current position of the trains can be divided into the following steps:

1. Finding the nearest vertex and edge of the graph - from the current position of the trains given the three-layer railway network model

2. Assessment of the relevancy of incoming GPS information from the communication terminal - verification whether the current position is not burdened by a disproportionate error (like, for example, that the distance of the trains from the nearest vertex/edge is a mere few meters or tens of metres, or that the trains is still assigned to the same super-edge, provided that it should still be located on it)

3. Calculation of the exact position of the trains on the edge of the model - using perpendicular projection of the point (current trains position) onto the line

The trains position data are collected from the communication terminals. These communication terminals sent position information to the central from 10 to 60 second (depends on configuration), Figure 3

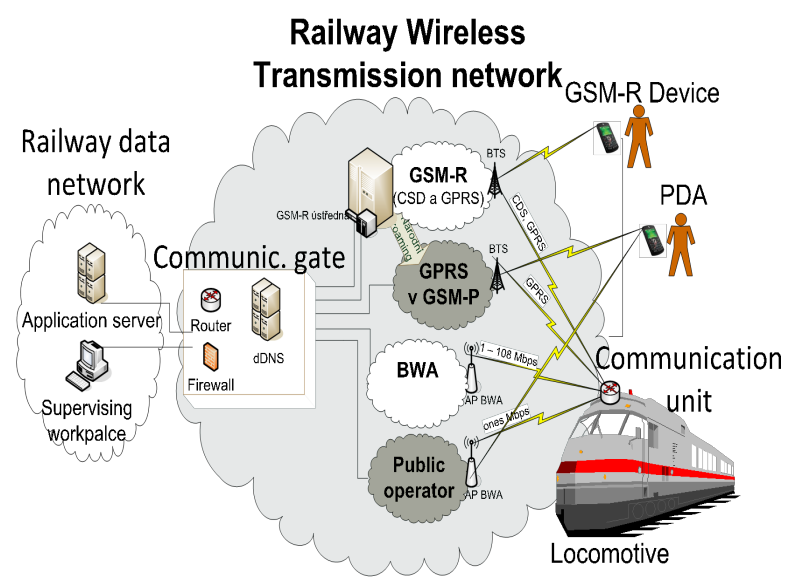

Figure 3 : Communication between the rail vehicle and dispatching centre

\section{RAILWAY NETWORK MODEL}

Undirected graph, as defined graph theory, is a natural candidate for a railway network model. Based on an analysis of data provided by the company SŽDC-TUDC (consisting of service regulations, passports, and codebooks), sets of algorithms were subsequently created, with which it was possible to generate a threelayer model of the rail network (Fikejz and Kavička, 2011). Roughly speaking, the track can be divided into individual so called supertracks, which consist of definition supra-sections (TDNU), where each suprasection contains track definition sections (TUDU) with mileposts (in hectometres). Basic aspects of the description of the rail network are collectively shown in Figure 4.

Mileposts (in hectometres) are shown in Figure with the distance in kilometres and are graphically represented using gray points. TUDU is recorded using a six-digit code $(163105,163106,16307,173202)$ and are graphically represented using solid lines (red, black, orange, brown). Individual supra-sections (CLS 007, CLS008, REG023) are shown in light blue and supertracks (B421021 1 and B421021 1A) are shown in dashed lines. A place significant in terms of transportation (branch line) is symbolized by a green square.

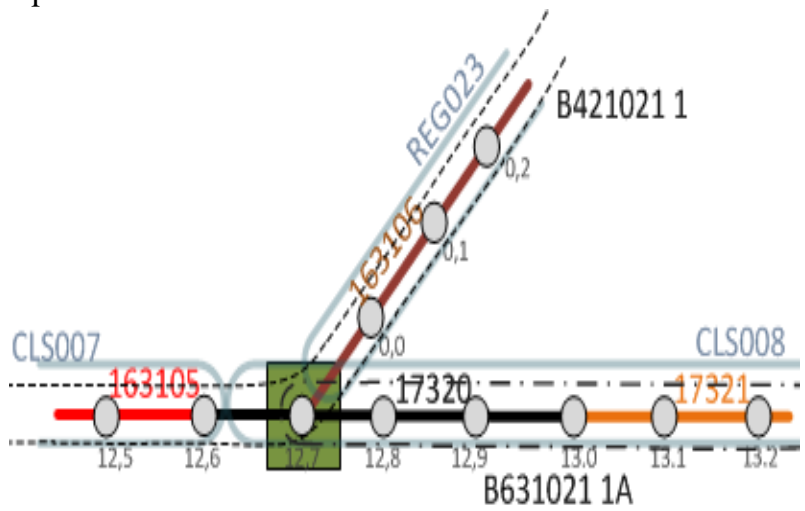

Figure 4: Basic aspects of the description of the rail network

The algorithm of railway network model (Fikejz and Kavička, 2011; Fikejz and Řezanina 2014.) was implemented directly on the database level using PL/SQL language. However, the algorithm had to be adjusted and generalized several times since there are various nonstandard conditions in the data, such as jumps in the mileposts (nonlinear growth of the kilometre succession between the mileposts) or change of an increasing kilometre sequence into a decreasing one and vice versa. The final model includes three data layers:

- Data-Micro, consisting of vertices and edges,

- Data-Mezo, include mezo-vertices and mezoedges

- Data-Macro, containing super-vertices and super-edges. 
Figure 5 presents the overall concept of a complete threelayer railway network model.

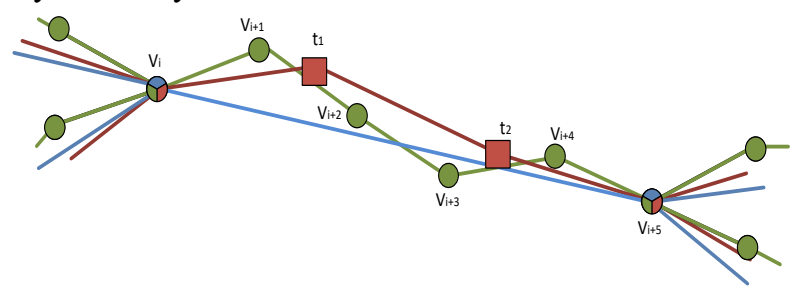

Figure 5: Illustration overall concept of a three-layer module

The data structure non-oriented graph was finally implemented directly in the ORCLE database using the ORACLE Spatial Network Data Model (Kothuri et al. 2007) technology. This technology enables the user to build a various network representation, involving also the object scheme and the communication interface API.

The objects scheme includes metadata and network tables. The interface contains on the server-side PL/SQL API (an SDO_NET packet) for the creation, control and analysis of the database network, and a middle layer Java API (on client's side) for the network analysis. The actual network is then defined by means of two compulsory tables:

- Node table,

- Link table.

For the work with spatial data, ORACLE with Spatial technology defines a special object data type SDO GEOMETRY, which enables its user to store a number of spatial information and geometric types, such as various points, arcs, linear chains or polygons.

\section{EVALUATION OF HISTORICAL POSITIONS OF TRAINS}

In order to create realistic conditions of future experiments, data of real trains were evaluated with a period of:

- 5 seconds,

- 10 seconds,

- 30 seconds,

- 60 seconds.

Individual records of train positions were subsequently processed by statistics. The current position of the train has always been evaluated from the point of view of the perpendicular projection of the nearest track of the observed route, see Figure 6.

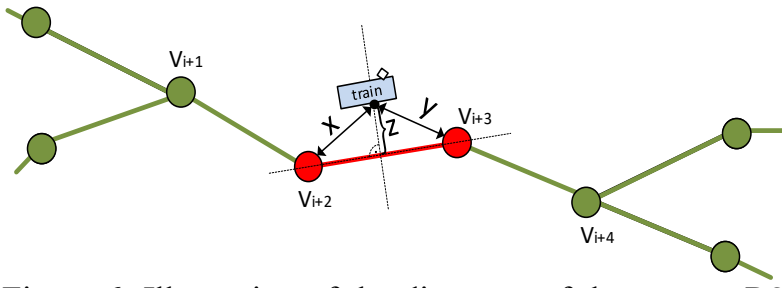

Figure 6: Illustration of the distances of the current RS position from the nearest vertices and edge of the infrastructure.

The database operator SDO_NN (nearest neighbours for a geometry) was used to find the nearest track and its distance. Overall, the following basic statistical indicators were evaluated:

- Average distance

- Minimum/Maximum Distance

- Median

- Standard deviation

Table 1: Resulting distance values from peaks and edges

\begin{tabular}{|l|c|c|}
\hline & $\begin{array}{l}\text { Distance from } \\
\text { vertex [m] }\end{array}$ & $\begin{array}{l}\text { Distance from } \\
\text { edge [m] }\end{array}$ \\
\hline Average & 26.54 & 7.03 \\
\hline Min & 0.41 & 0.1 \\
\hline Max & 80.26 & 69.17 \\
\hline Median & 26.53 & 3.69 \\
\hline $\begin{array}{l}\text { Standard } \\
\text { deviation }\end{array}$ & 14.67 & 11.45 \\
\hline
\end{tabular}

However, the table above does not consider situations in which the rolling stock is located/ is not located on the open line or in the railway station. The designed model does not fully reflect the reality of the track infrastructure in railway stations that can have a high number of shutdown tracks. These tracks are not considered by the model and are replaced by one or more continuous tracks. Therefore, it is clear that at stations the calculated distances of the current position of the rolling stock to the vertices and edges will be considerably higher.

Further experiments focus on two other subvariants, in which the rolling stock was located on the wide line or in the perimeter of the railway station. The resulting assessment is shown in Tables 2 and 3 
Table 2: Result values of distances from vertices in railway station and on the wide line

\begin{tabular}{|l|c|c|}
\hline & $\begin{array}{l}\text { Distance from } \\
\text { vertex in station } \\
{[\mathrm{m}]}\end{array}$ & $\begin{array}{l}\text { Distance from } \\
\text { vertex on the wide } \\
\text { line [m] }\end{array}$ \\
\hline Average & 28.68 & 24.63 \\
\hline Min & 1.68 & 0.44 \\
\hline Max & 28.26 & 50.68 \\
\hline Median & 15.40 & 26.53 \\
\hline $\begin{array}{l}\text { Standard } \\
\text { deviation }\end{array}$ & \multicolumn{2}{|}{} \\
\hline
\end{tabular}

Table 3: Resulting values of distances from the edges in the railway station and on the wide line.

\begin{tabular}{|l|c|c|}
\hline & $\begin{array}{l}\text { Distance from edge } \\
\text { in station }[\mathrm{m}]\end{array}$ & $\begin{array}{l}\text { Distance from } \\
\text { edge on wide line } \\
{[\mathrm{m}]}\end{array}$ \\
\hline Average & 11.33 & 3.25 \\
\hline Min & 0.01 & 0.1 \\
\hline Max & 69.15 & 24.63 \\
\hline Median & 6.11 & 2.50 \\
\hline $\begin{array}{l}\text { Standard } \\
\text { deviation }\end{array}$ & 15.37 & 2.93 \\
\hline
\end{tabular}

The tables show how the distance values of the current position of the rolling stock on the wide line differ from the distance in stations. If we focus on Table 8, which is of the highest importance for us from the point of view of monitoring train on regional lines, then we can note significant differences between the values of distances in station and outside it. When observing the median, whose value divides the observed set in half, the distance difference is more than double.

From the point of view of evaluating the accuracy of the calculation of the position of the rolling stock relative to the model of the railway network, for the overall monitored set of input data (railway station + wide line) the distance from model edges is up to 10 meters in $88 \%$ of cases. If we then focus only on wide single-track lines, then the distance of the rolling stock position from the edge of the model up to 10 meters occurs in $\mathbf{9 8 , 5} \%$ of cases.

\section{DETECTION OF NON-STANDARD STATES}

A situation where two rolling stock (trains) occur below a defined boundary distance can be considered as a nonstandard or a crisis within single-track lines. From the point of view of the movement of the rolling stock, we can follow:

- the opposite running of trains;

- parallel running of trains

○ a faster vehicle approaching a slower moving vehicle
In the simplest case, it would be possible to test great circle distance, however, this solution has limitations, for example, when crossing lines or in non-linear course of the line, see Figure 7.

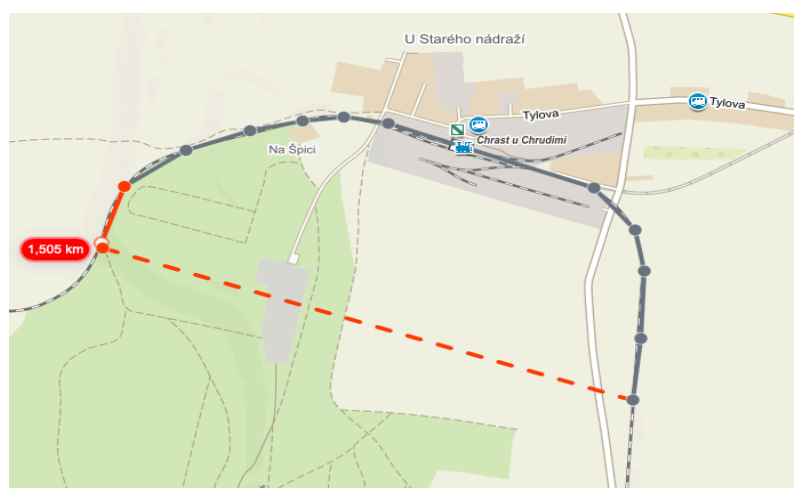

Figure 7: Real vs. great circle distance

The above example illustrates the problem of accessing great circle distance in relation to the track profile. The real distance (grey curve) is $2.251 \mathrm{~m}$, whereas the great circle distance of the track objects (red dashed line) corresponds to $1.514 \mathrm{~m}$ which is almost 1.5 times the real length.

For a more realistic calculation of distances of two rolling stock, the described multi-layered model of the railway network reflecting an non-oriented graph is used, in combination of data layers Data-Micro and DataMezo. The data layer is used to detect non-standard situations, i.e. when two rolling stock occurs on:

- $\quad$ an identical edge,

- $\quad$ adjacent edges.

Both approaches can be seen in Figure. 8 and 9.

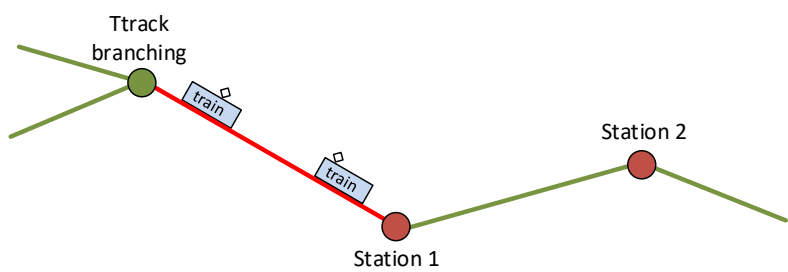

Figure 8: Illustration of detection of two rolling stock on identical edge

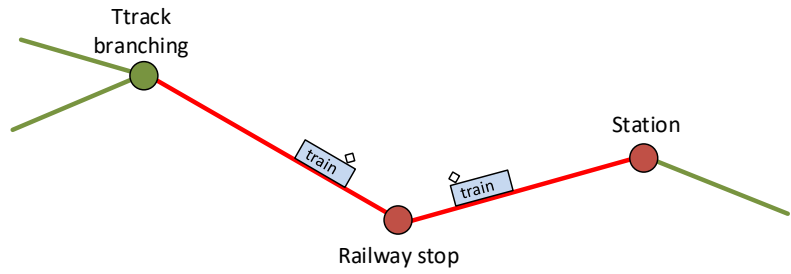

Figure 9: Illustration of detection of two rolling stock on two edges. 
The Data-Micro data layer is then used to calculate the distance of two observed rolling stock. The data layer has the smallest degree of abstraction, with each edge being $100 \mathrm{~m}$ long.

\section{EXPERIMENTS}

A computer simulation, which induces the operation of the rolling stock, was used for the detection of nonstandard situations. The simulator used data based on real conditions which were based on historical data processing of trains.

Individual experiments of non-standard situations can be divided into three groups:

- The opposite running of trains;

- Simultaneous train running,

- One train is on halt, the other is moving.

and further it is possible to distinguish between situations where two trains occur on:

- Single/identical edge

- Two adjacent edges.

In the following experiment, attention was focused on the opposite direction running of two trains, and it was observed how far apart they are at the time of detection of each train set when the train location is transmitted every:

- 5 seconds,

- 10 seconds,

- 30 seconds,

- 60 seconds.

\subsection{Results of experiments}

If we focus on detecting the opposite direction running on an identical rail/edge (as shown in Figure 8), then their distances at the time of detection can be statistically expressed according to Table 4.

Table 4: Resulting distances [m] at the time of detection of two trains on an identical edge.

\begin{tabular}{|l|c|c|c|c|}
\hline & $\begin{array}{c}\text { Period } \\
5[\mathrm{~s}]\end{array}$ & $\begin{array}{c}\text { Period } \\
10[\mathrm{~s}]\end{array}$ & $\begin{array}{c}\text { Period } \\
30[\mathrm{~s}]\end{array}$ & $\begin{array}{c}\text { Period } \\
60[\mathrm{~s}]\end{array}$ \\
\hline Min & 1000 & 1000 & 600 & 0 \\
\hline Max & 2500 & 2500 & 2400 & 2400 \\
\hline Average & 2016 & 1968 & 1628 & 1140 \\
\hline Median & 2100 & 2100 & 1800 & 900 \\
\hline $\begin{array}{l}\text { Standard } \\
\text { deviation }\end{array}$ & 396,67 & 413,49 & 519,63 & 726,64 \\
\hline
\end{tabular}

The table above shows that both average and median decrease with increasing time frequency, while the standard deviation increases. The frequency of 60 seconds is unequivocally unsatisfactory, when in two cases a collision has already occurred. The 30-second period also appears unsatisfactory for single-track regional lines where the train speed is lower than on the main routes.

In the latter case, the detections of opposite direction running on two adjacent rails/edges were evaluated according to the approach shown in Figure 9. The results can be seen in Table 5 .

Table 5 : Resulting distances $[\mathrm{m}]$ at the time of detection of two trains on two adjacent edges.

\begin{tabular}{|l|c|c|c|c|}
\hline & $\begin{array}{c}\text { Period } \\
5[\mathrm{~s}]\end{array}$ & $\begin{array}{c}\text { Period } \\
10[\mathrm{~s}]\end{array}$ & $\begin{array}{c}\text { Period } \\
30[\mathrm{~s}]\end{array}$ & $\begin{array}{c}\text { Period } \\
60[\mathrm{~s}]\end{array}$ \\
\hline Min & 2500 & 2500 & 2000 & 1400 \\
\hline Max & 3900 & 3900 & 3600 & 3600 \\
\hline Average & 3084 & 3064 & 2776 & 2624 \\
\hline $\begin{array}{l}\text { Median } \\
\text { deviation }\end{array}$ & 3000 & 3000 & 2700 & 2700 \\
\hline
\end{tabular}

Table 5 shows that compared to the results of the first experiment (Table 4), where the values of median and standard deviations were approximately double, significantly lower distance differences, namely in all monitored parameters, can be seen in this case.

\section{CONCLUSION}

This article was primarily focused the use of computer simulation for induction and detection of nonstandard/crisis situations within regional and single-track lines. First, attention is paid to data collection of real passes within the selected segment of the railway network. Subsequently, this data was processed statistically. The evaluated results of the distances of the current position of the rolling stock from the edge and vertices showed the same parameters/deviations as historical data from another segment of the railway network.

The results of the analysed data were then used for parametrization of the designed simulator, allowing for the simulation of rolling stock operation. The simulator was used in the next phase for experiments involving induction of non-standard/crisis situations within the selected segment of the railway infrastructure model. The experiments included different running scenarios, and at this stage of the research, the distance within which the rolling stock is located was initially observed when the crisis/non-standard situation was detected.

\section{ACKNOWLEDGMENTS}

The work was supported from ERDF/ESF " Cooperation in Applied Research between the University of Pardubice and companies, in the Field of Positioning, Detection and 
Simulation Technology for Transport Systems (PosiTrans)" (No. CZ.02.1.01/0.0/0.0/17_049/0008394)

\section{REFERENCES}

Dorazil, P. Základní vlastnosti kolejových obvodů bez izolovaných styků. Pardubice, 2008. Bachelor thesis. University of Pardubice. Supervisor: Milan Kunhart.

Fikejz, J. and A. Kavička. Utilisation of computer simulation for testing additional support for dispatching rail traffic. In: European Simulation and Modelling Conference, 2011. Ostende: EUROSIS - ETI, 2011. p. 225-231. ISBN 978-9077381-66-3.

Fikejz, J. and E. Řezanina, Utilization of computer simulation for detection non-standard situations within the new data layer of railway network model. In: The 26th European Modeling \& Simulation Symposium. Bordeaux, 2014s. 371-377, ISBN 97888-97999-32-4

Kolář, P. Řizeni provozu na vedlejšich železničnich tratich. Seminár ZČU Plzeň-Fakulta elektrotechnická [online]. 2014 [cit. 2014-12-12]. http://old.fel.zcu.cz/Data/documents/sem_de_2014 /5-RB_Kolar.pdf

KOM 2011) 144 - WHITE PAPER - A Roadmap to a Single European Transport Area - Creating a competitive and resource efficient transport system.

Kothuri, R. et al. Pro Oracle Spatial for Oracle database 11g. New York, NY: Distributed to the book trade worldwideby Springer-Verlag New York, c2007, xxxiv, 787 p. ISBN 15-905-9899-7.

Libbrecht, R. and H. Sturesson. LOCOPROL: Final Report [online]. 2005 [cit. 2015-06-10].: http://www.transport- research.info/Upload/Docu ments/200607/20060727_153639_69273_LOCOP ROL_Final_Report.pdf

Low cost ERTMS implementation: ERTMS Regional. Railwaysignalling [online]. 2014 [cit. 2016-01-02]. $\mathrm{http} / / / \mathrm{www}$.railwaysignalling.eu/ertms-regional

Mouna L. Integrated Applications Promotion Programme: Train Integrated Safety Satellite System (3InSat) Demonstration project, Rome 2013,[online]. [cit. 2015-06-10]. https://artesapps.esa.int/sites/default/files/1IAP\%20ASTS\%203InSat_18-04-2013.pdf

Redding, L. Satloc: a high-tech saviour for low-density lines. Railjournal [online]. UK, 2014 [cit. 2016-0102].

http://www.railjournal.com/index.php/telecoms/sat loc-a-high-tech-saviour-for-low-densitylines.html?channel $=533$ 